\title{
ADAPTIVE SYSTEM OF FUZZY-LOGICAL REGULATION BY TEMPERATURE MODE OF A DRUM BOILER
}

\author{
SIDDIKoV ISAMIDDIN XAKIMOVICH ${ }^{1}$, UMURZAKOVA DILNOZA MAXAMADJONOVNA ${ }^{* 1}$ \\ AND BAKHRIEVA HURSHIDA ASKARXODJAEVNA ${ }^{2}$ \\ ${ }^{1}$ Department of Information Processing Systems and Management, \\ Tashkent State Technical University, 100097 Tashkent, Uzbekistan \\ ${ }^{2}$ Department of Multimedia Technology, Tashkent University of Information Technologies, \\ 100200 Tashkent, Uzbekistan \\ *Corresponding author: umurzakovadilnoz@gmail.com
}

(Received: 13 $3^{\text {th }}$ August 2019; Accepted: $14^{\text {th }}$ October 2019; Published on-line: $20^{\text {th }}$ January 2020)

\begin{abstract}
The article discusses the creation of an adaptive system for managing dynamic objects based on neuro-fuzzy technology. This technology is used to actively identify and create temperature control algorithms for the superheated steam of a drum boiler in the presence of disturbances associated with a change in load. To solve this problem, the use of a fuzzy-logical controller is proposed. The rule base of this regulator is defined. A technique is proposed for determining the optimal number of neurons and the number of hidden layers. The neuro-fuzzy model of the controller is presented in the form of a multilayer neural network without feedback, which is characterized by a simple implementation in practice. The use of a fuzzy-logical controller gives the automatic control system the ability to maintain technological parameters at a given level in the presence of external disturbing influences, and also makes it possible to efficiently control the process.
\end{abstract}

ABSTRAK: Artikel ini membincangkan rekaan sistem penyesuaian bagi mengurus objek dinamik berdasarkan teknologi neura-kabur. Teknologi ini digunakan bagi mengenal pasti secara aktif dan mencipta algoritma kawalan suhu bagi stim melampau panas dalam drum dandang dengan kehadiran gangguan berkaitan perubahan beban. Bagi menyelesaikan masalah ini, penggunaan pengawal logik-kabur telah dicadangkan. Asas peraturan bagi pengaturan ini ditentukan. Satu teknik dicadangkan bagi mendapat bilangan optima neuron dan bilangan lapisan tersembunyi. Model neura-kabur pengawal ini dikemukakan dalam bentuk rangkaian neural berlapis tanpa suap balik, bercirikan praktik pelaksanaan mudah. Penggunaan pengawal logik-kabur memberi sistem kawalan automatik kebolehan mengekalkan parameter teknologi pada tahap tertentu dengan kehadiran pengaruh gangguan luar, dan juga memberi kebolehan proses kawalan yang cekap.

KEYWORDS: fuzzy model; PID-controller; neural networks; drum boiler; controller; adaptive system; temperature; heat power industry

\section{INTRODUCTION}

Currently, in most industrial facilities, including heat and power facilities for process control, PID controllers have found wide application. About 90-95 \% of the regulators currently in operation use the PID algorithm. The reasons for such popularity are their 
simplicity of construction, clarity of operation, suitability for most practical tasks, and low costs.

In existing thermal power facilities, a typical cascade system for superheated steam temperature control is used, which includes the control circuit of the proportional-integral (PI) regulator and the additional measurement loop of the auxiliary controlled variable formed in the signal conditioning unit.

Analysis of the operating characteristics of the superheater shows that the control object has a variable transport lag, its dynamic properties substantially depend on the oxygen content in the outgoing gases, contamination of heating surfaces, and regime factors - load, type, and grade of fuel burned, condition of heating surfaces, excess air, etc. [2]. In addition, obtaining a mathematical model of superheated steam temperature is usually associated with approximation of acceleration curves obtained experimentally, as a result of which the mathematical description becomes a priori inaccurate.

The study of scientific publications in the field of adaptive ARS (Automatic Control Systems) in dynamic systems $[1,2]$ led to the conclusion that traditional methods of active identification and associated algorithms for calculating optimal settings for PI and PID controllers that analyse the complex frequency response of objects or the self-oscillation mode are widely used. It should be noted that for the considered ACS of the temperature of the steam, the self-oscillation process is unacceptable due to the requirements of the technological regulations, since a deviation of the steam temperature from the norm can lead to premature wear of the turbine equipment. Thus, the scientific problem arises of finding the optimal methods for identifying an object in cases of changes in its load and algorithms for calculating PI controller settings to ensure the expected transition process (by overshoot $\mathrm{G}<30 \%$, attenuation degree, with minimum control time $T_{r}$ ) [1,2].

The use of PID-law in power engineering leads to an increase in the quality of regulation. With regard to the ACS of the steam temperature, the use of the PID-law of regulation allows maintaining temperature fluctuations more accurately in the whole steam output range of the boiler unit, which is a top priority. The use of the PID algorithm is limited by the complexity of its setup. This is due to the peculiarity of ACS operation with PID controllers: high sensitivity to deviation of their optimum settings and the impossibility of applying the step method for obtaining the type of transient process.

A disadvantage of the known methods of setting the parameters of the PID controller is the incomplete information about the system stability margin and robustness. Safety margin and robustness determines the reliability of the regulator. To consider these factors, an analysis is needed to change the dynamics of the control object and, in this case, obtain a transient response of the control object, model the control object taking into account the range of changes in dynamic characteristics, and go to settings that are close to optimal and do not need significant additional tuning.

The algorithms of operation of automated control systems developed at the design stage, as a rule, differ significantly from the optimal values of the parameters of traditional regulators. This is due to the imperfection of mathematical models of objects. It is known that obtaining mathematical models of experimental control systems for operating complex objects is a difficult task. These difficulties are associated with the influence of external and parametric perturbations, some of which are non-stationary in nature and are not subject to control [3].

In this regard, it is necessary to use adaptive intelligent control systems for complex multi-mode dynamic objects, which include drum boilers, using neuro-fuzzy technology 
and the necessary measure to improve the efficiency of production management in general.

\section{RESEARCH METHODS}

Currently, scientific approaches associated with the use of intelligent systems $[5,6]$, based on the hybrid application of neural regulators and neural networks, have become widely popular in the theory of adaptive control, which prompted the emergence of a new scientific direction - hybrid, or neuro-fuzzy networks (HN, NFN) [4]. Consideration of this technology in relation to the identification and adaptation of the ACS of the temperature of superheated steam is an important scientific task.

The control parameters of the fuzzy PID controller include fuzzy parameters, fuzzy inference rules, and the resolution of the parameters of the fuzzy PID controller. Based on the setup input and the feedback signal, the computer calculates the deviation and the current change in the deviation of the actual position and the theoretical position. It then processes the fuzzy reasoning according to a fuzzy rule. Finally, the fuzzy parameters were processed by a fuzzy solution and output a proportional (P), integral (I), and differential (D) coefficients of the PID controller.

As an object of regulation, we consider the automatic control system (ACS) of the temperature of the superheated steam of a drum boiler $[1,2]$. The task of controlling the superheater was to provide a predetermined temperature in the steam path of the boiler. The steam temperature is changed by increasing or decreasing the amount of water injected into the superheater to stabilize the set value of the steam temperature at the superheater outlet.

To solve this problem, we will use intelligent control methods, in particular, the fuzzy logic method. This allows synthesis of process control systems in the class of neural network systems.

The task is then to stabilize the controlled variable with a given quality of the transition process with incomplete information about the control object and to obtain invariance properties to external disturbing influences of the automatic control system.

To solve the problem, it is necessary to [3]:

1. Describe the control object and define its input and output parameters and disturbing influences.

2. Choose the fuzzy inference algorithm that most fully determines the decisions made under the given conditions of the process.

3. Synthesise a fuzzy controller, which is an integral part of an intelligent controller and provides the required qualitative and quantitative indicators of temperature control in the presence of disturbing influences.

4. Investigate the obtained response surfaces of a fuzzy regulator under the conditions of the presence of disturbing influences and a pure delay characterizing the technological process.

As a control object (Fig. 1), we consider a superheater with a thermocouple. The transfer function obtained as a result of processing a family of acceleration curves [6], we write in explicit form as follows: 


$$
W_{F M}(s)=\frac{y(s)}{v(s)}=\frac{K \cdot e^{-s \cdot \tau}}{a_{3} \cdot s^{3}+a_{2} \cdot s^{2}+a_{1} \cdot s+1} \cdot \frac{m_{C h C T}}{T_{C h C T} \cdot+1}
$$

where s is a complex variable; $y(s)$ and $v(s)$ - images of scalar functions of output and input of an object; $K$ - injection ratio; $\tau$ - transport delay; $a_{1}, a_{2}, a_{3}$ - parameters of the characteristic equation of the function; $W_{F M}(s) ; T_{C h C T}=$ const and $m_{C h C T}=$ const - time constant and static coefficient of a chromel-copel thermocouple.

Based on the technological regulations for a particular superheater, the interval of change of parameters is represented by the following relations:

$$
\begin{aligned}
& 2.8=K^{(-)} \leq K \leq K^{(+)}=4.6, \quad 45=\tau^{(-)} \leq \tau \leq \tau^{(+)}=141, \\
& 15=T_{C h C T}^{(-)} \leq T_{C h C T} \leq T_{C h C T}^{(+)}=20, \quad 244=a_{1}^{(-)} \leq a_{1} \leq a_{1}^{(+)}=393, \\
& 20160=a_{2}^{(-)} \leq a_{2} \leq a_{2}^{(+)}=61920, \quad 345600=a_{3}^{(-)} \leq a_{3} \leq a_{3}^{(+)}=3909600 \\
& \xi=\operatorname{col}\left(K, h, T_{C h C T}, a_{1}, a_{2}, a_{3}\right) \in \Xi,
\end{aligned}
$$

where the superscripts ${ }^{(-)}$and ${ }^{(+)}$- are the values of the boundaries of the coefficients that determine the known set $\Xi ; \xi \in \Xi$ - vector of unknown parameters.

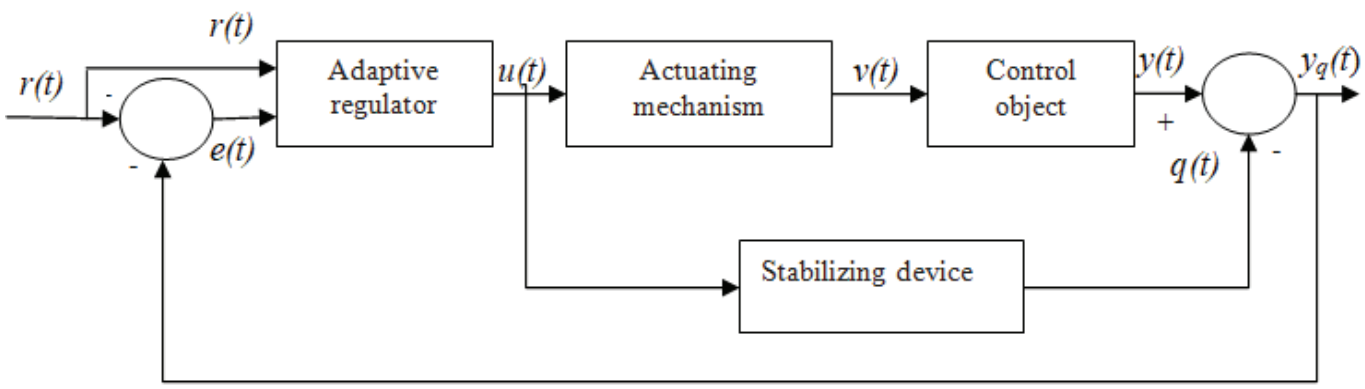

Fig. 1: The main circuit control temperature superheater.

The transfer function of the actuator (which moves the regulating body of the control object - the valve), taking into account its inertia with respect to the object, will be described as

$$
W_{C A}(s)=\frac{v(s)}{u(s)}=\frac{1}{T_{C A} \cdot s},
$$

where $T_{C A}=$ const is the time constant of the actuator.

The structure of the adaptive controller, taking into account the neuron, is given in the form

$$
\begin{aligned}
& u(s)=\frac{K_{2} \cdot s}{T_{0} \cdot s+1} \cdot g(s) ; \\
& g(t)=\wp(t) \cdot r(t) ; \\
& \wp(t)=f(e(t), r *)=\frac{1}{1+e^{\alpha \cdot\left(w \cdot e(t)+w_{0}\right)}} ;
\end{aligned}
$$




$$
\begin{aligned}
& r(t)=r *=\text { const } ; \\
& e(t)=r * y_{q}(t)=r *-y(t)-q(t),
\end{aligned}
$$

where $K_{2}$ and $T_{0}$ - the transmission coefficient and the time constant of the linear part of the adaptive controller; $u(s)$ - control action; $g(t)$ - the output of the nonlinear part of the adaptive controller represented by a single neuron with a sigmoid activation function $\wp(t)$ and weighting coefficients $w$ and $w_{0}$. The input of the neuron is a generalized regulation error $e(t) ; r(t)$ - setting effect equal to the value $r *$ in the stabilization mode; $y_{q}(t)$ generalized output control system of the form $y_{q}(t)=y(t)+q(t)$.

The proposed system differs in that, in the control circuit, there is a single fuzzy-logic controller (FLC) with two inputs and one output. The fuzzy controller is assigned the task of generating a control action in the range of variation of the dynamic regulation error and it is integral with respect to its threshold values. Therefore, when synthesizing a fuzzy controller, we use the Mamdani output algorithm [4] as the simplest one. Although the Mamdani algorithm is recommended for use in other areas (expert systems and decisionmaking systems), it can work effectively in the development of fuzzy process control systems.

As you know, a fuzzy controller consists of three main blocks: the fuzzification block, the fuzzy output block and the defuzzification block. In the first block, it is necessary to fuzz the input signals, i.e. translate well-defined signals into fuzzy form. To do this, we first determine the number of fuzzy statements for each input signal, which will be operated by the FLC knowledge base and is a meaningful component of the fuzzy output block. To fill an initially empty knowledge base, you must define a management goal.

In this case, the goal of control is to maintain the technological parameter in a given range of deviations from the desired value in the event of controlled and uncontrolled disturbances. In this case, the more the deviation of the technological parameter from the threshold value increases, the greater should be the increment that changes the coefficient of transfer of the regulator.

FLC has two input signals:

$$
\begin{aligned}
& e_{1}=\left(\text { "error", } A_{e 1}, e_{1}^{\text {min }} ; e_{1}^{\text {max }} ; \mid\right) ; \\
& e_{2}=\left(\text { "integral error", } A_{e 2},\left(e_{2}^{\text {min }} ; e_{2}^{\text {max }} ; \mid\right) .\right.
\end{aligned}
$$

For the $e_{1}$ signal, we write the following statements:

' $N B_{e 1}{ }^{\prime}-\ll$ Deviation of steam temperature is negatively large»;

' $N M_{e 1}{ }^{\prime}-$ «Deviation of steam temperature is negatively average»;

' $N S_{e 1}{ }^{\prime}-\ll$ Deviation of steam temperature is negatively small»;

' $Z E_{e 1}{ }^{\prime}-\ll$ Deviation of steam temperature near zero»;

' $P S_{e 1}{ }^{\prime}-$ «The deviation of the temperature of the steam is positively small»;

' $P M_{e 1}$ '- «Temperature deviation of steam is positively average»; 
' $P B_{e 1}{ }^{\prime}-\langle$ Deviation of steam temperature is positively large.»;

Then the term - sets of the linguistic variable "Error" can be defined as:

$$
A_{e 1}=\left\{N B_{e 1}, N M_{e 1}, N S_{e 1}, Z E_{e 1}, P S_{e 1}, P M_{e 1}, P B_{e 1}\right\} \text {. }
$$

In the same way we will define a term - a set of the linguistic variable "Integral. Error" as:

$$
A_{e 2}=\left\{N B_{e 2}, N M_{e 2}, N S_{e 2}, Z E_{e 2}, P S_{e 2}, P M_{e 2}, P B_{e 2}\right\} .
$$

If we consider that FLC has an output signal $u=F u z z y\left(e_{1}, e_{2}\right)$, then its output linguistic variable can be represented as:

$$
u=\left(\text { "Control", } A_{u},\left[u^{\min } ; u^{\max }\right]\right),
$$

where $A_{u}=\left\{N B_{u}, N M_{u}, N S_{u}, Z E_{u}, P S_{u}, P M_{u}, P B_{u},\right\}$;

' $N B_{u}{ }^{\prime}-\ll$ Water consumption is negatively large»;

' $N M_{u}{ }^{\prime}-\ll$ Water consumption is negative average»;

' $N S_{u}{ }^{\prime}-\ll$ Negatively low water consumption»;

' $Z E_{u}{ }^{\prime}-\ll$ Water flow around zero»;

'PS ${ }^{\prime}$ - «Positively low water flow»;

' $P M_{u}{ }^{\prime}-\ll$ Water consumption is positively average»;

' $P B_{u}{ }^{\prime}-\ll$ Positively large water flow».

Operating with the received input and linguistic variables, the goal of management will build a knowledge base for the fuzzy logic controller (Table 1).

Choosing linguistic variables and making up the knowledge base of FLC, you can proceed to the phase of fuzzification, the purpose of which is to establish the correspondence between the specific values of individual input and output variables of the fuzzy logic controller and the values of the membership functions of the corresponding thermal linguistic variables. At the end of this stage, the specific values of the membership functions for each of the linguistic terms should be defined. Table 1 applies to all linguistic variables.

Table 1: Values of membership functions for all linguistic variables

\begin{tabular}{cccccccccc}
\hline \multirow{2}{*}{$e_{1}$} & $N B_{e 1}$ & $N M_{e 1}$ & $N S_{e 1}$ & $Z E_{e 1}$ & $P S_{e 1}$ & $P M_{e 1}$ & $P B_{e 1}$ & $N B_{e 1}$ & $N M_{e 1}$ \\
\cline { 2 - 9 } & $N B_{u}$ & $N B_{u}$ & $N B_{u}$ & $N B_{u}$ & $N M_{u}$ & $N S_{u}$ & $Z E_{u}$ & $N B_{u}$ & $N B_{u}$ \\
$N B_{e 1}$ & $N B_{u}$ & $N B_{u}$ & $N B_{u}$ & $N M_{u}$ & $N S_{u}$ & $Z E_{u}$ & $P S_{u}$ & $N B_{u}$ & $N B_{u}$ \\
$N M_{e 1}$ & $N B_{u}$ & $N B_{u}$ & $N M_{u}$ & $N S_{u}$ & $Z E_{u}$ & $P S_{u}$ & $P M_{u}$ & $N B_{u}$ & $N B_{u}$ \\
$N S_{e 1}$ & $N B_{u}$ & $N M_{u}$ & $N S_{u}$ & $Z E_{u}$ & $P S_{u}$ & $P M_{u}$ & $P B_{u}$ & $N B_{u}$ & $N M_{u}$ \\
$Z E_{e 1}$ & $N M_{u}$ & $N S_{u}$ & $Z E_{u}$ & $P S_{u}$ & $P M_{u}$ & $P B_{u}$ & $P B_{u}$ & $N M_{u}$ & $N S_{u}$ \\
$P S_{e 1}$ & $N S_{u}$ & $Z E_{u}$ & $P S_{u}$ & $P M_{u}$ & $P B_{u}$ & $P B_{u}$ & $P B_{u}$ & $N S_{u}$ & $Z E_{u}$ \\
$P M_{e 1}$ & & & & & & & & & \\
\hline
\end{tabular}


Further, the Mamdani output algorithm is used, which formally consists of the following:

- Aggregation of sub-conditions in fuzzy rules. To find the degree of truth of the conditions of each of the rules, fuzzy logic operations are used. Those rules, and the degree of truth that is non-zero, are considered active and are used for further calculations. $[5]:$

- Activation of sub-conclusions in fuzzy rules is carried out according to the formula

$$
\mu^{\prime}(y)=\min \left\{c_{1}, \mu(x)\right\},
$$

where $\mu(x)$ is the term membership function, which is the value of some input variable; $c_{1}$ - the degree of truth of the sub-conclusions for each of the rules.

- Accumulation of conclusions fuzzy rules of production. Fuzzy sets are merged, corresponding to the terms of the subclasses belonging to the same output linguistic variables:

$$
\mu_{e(i) \cup \int e(t) d t}(x)=\max \left\{\mu_{A_{e 1}}(x), \mu_{A_{e 2}}(x)\right\},
$$

where $\mu_{A_{e 1}}(x), \mu_{A_{e 2}}(x)$ are the membership functions of the merged fuzzy sets $A_{e 1}$ and $A_{e 2}$.

- Calculation of control variable values at the output of a fuzzy controller. To do this, it is necessary to find the function of belonging to a variable to a set formed as a result of executing output operations on sets included in the rule system (Table 1).

The membership functions for each of the sets $A_{u}=\left\{N B_{u}, N M_{u}, N S_{u}, Z E_{u}, P S_{u}, P M_{u}, P B_{u},\right\}$ included in the fuzzy variable $\tilde{u}$ in the inference rules are defined as:

$$
\begin{aligned}
& \mu_{R_{1}}(\tilde{u})=\min \left\{\mu_{v 1}(\tilde{u}), \min \mu_{e_{1,1}}(e), \mu_{e_{2,1}}\left(\int e d t\right)\right\}, \\
& \mu_{R_{2}}(\tilde{u})=\min \left\{\mu_{v 2}(\widetilde{u}), \min \mu_{e_{1,2}}(e), \mu_{e_{2,2}}\left(\int e d t\right)\right\} \text {, } \\
& \mu_{R_{3}}(\widetilde{u})=\min \left\{\mu_{v 3}(\widetilde{u}), \min \mu_{e_{1,3}}(e), \mu_{e_{2,3}}\left(\int e d t\right)\right\} \text {, } \\
& \mu_{R_{49}}(\tilde{u})=\min \left\{\mu_{v 3}(\tilde{u}), \min \mu_{e_{1,49}}(e), \mu_{e_{2,49}}\left(\int e d t\right)\right\} .
\end{aligned}
$$

Here, each of the 49 equations corresponds to one of the rules (Table 1). The resulting membership function of the control action $\tilde{v}$, obtained after the application of all 49 rules, is found as the union of the membership functions of all rules:

$$
\mu(\tilde{u})=\max \left\{\mu_{R_{1}}(\widetilde{u}), \mu_{R_{2}}(\tilde{u}), \ldots, \mu_{R_{49}}(\tilde{u})\right\} .
$$

- Defusing output variables. Now that the resulting membership function of the control action is obtained, the question arises as to which particular value of control action $\widetilde{v}$ should be chosen. If we use the probabilistic interpretation of the theory of fuzzy sets, it becomes clear that such a value can be obtained by analogy with the mathematical expectation of the control action in the form: 


$$
u=\left[\int_{\min }^{\max } \tilde{u} \mu(\tilde{u}) d \tilde{u}\right] /\left[\int_{\min }^{\max } \mu(\tilde{u}) d \tilde{u}\right] .
$$

To determine the tuning values of the neuron weighting coefficients, we perform the following procedure, let's set the mode of the system stabilization process described by the equations:

$$
\begin{aligned}
& y_{q^{*}}=K_{2} \cdot K \cdot m_{C h C T} \cdot T_{C A}^{-1} \cdot g *, \\
& g^{*}=\wp_{0} \cdot r^{*}, \\
& \wp_{0}=f\left(e^{*}, r^{*}, \infty\right), q^{*}=0, e^{*}=r^{*}-y_{q^{*}}=r^{*}-y^{*}=0,
\end{aligned}
$$

Where index $*$ is the designation of the steady-state values of the corresponding variables. Equations (12) - (14) can be combined and represented identically as an expression

$$
y_{q^{*}}=K_{2} \cdot K \cdot m_{C h C T} \cdot T_{C A}^{-1} \cdot \wp_{0} \cdot r^{*},
$$

Which is often called the implicit reference model equation. In particular, from (15) it follows, taking into account the equality $y_{q^{*}}=r^{*}$, that the value $\wp_{0}=$ const always exists and is determined by the expression

$$
\wp_{0}=\frac{T_{C A}}{K_{2} \cdot K \cdot m_{C h C T}} .
$$

The adaptive fuzzy-logic controller is configured using the weighting coefficients of artificial neural networks, using the back-propagation error algorithm.

In this case, the output signal $\wp(\tau)$ of the neuron $\tau$-th time is defined as $(\tau=1,2, \ldots)$

$$
\wp(\tau)=f(\sigma(\tau))=\frac{1}{1+e^{-\alpha \sigma(\tau)}},
$$

where

$$
\sigma(\tau)=w_{0}+w(\tau) \cdot e(\tau) .
$$

Thus we get a lot of output signals

$$
\begin{aligned}
& \wp_{1}\left(\tau_{1}\right), \ldots, \wp_{i}\left(\tau_{i}\right), \ldots, \wp_{n}\left(\tau_{n}\right), \\
& E(\tau)=\frac{1}{2}[\varepsilon(\tau)]^{2}=\frac{1}{2}\left[\wp_{0}-\wp(\tau)\right]^{2} .
\end{aligned}
$$

which is subject to the condition $\lim _{t \rightarrow \infty} y(t)=y^{*}=r^{*}=$ const, corresponds to the reference value of the output signal $\wp_{0}=$ const, i.e. $\lim _{n \rightarrow \infty} \wp_{n}\left(\tau_{n}\right)=\wp_{0}=$ const .

In our case, the reference output will be (16), and the reference input will be $e^{*}=0$.

We formulate a measure of error, based on a comparison of signals (16) and (19), we define the half-sum of the squares of the differences

For the correction of the weighting coefficient $w$, we will use the method of fastest descent, which is the most simple to implement. 


$$
w(\tau+1)=w(\tau)+y \frac{d E(\tau)}{d w(\tau)}
$$

where $y>0$ determines the size of the correction step. Here, it is necessary to take into account that

$$
\frac{d E(\tau)}{d w(\tau)}=\frac{d E(\tau) d \sigma(\tau)}{d \sigma(\tau) d w(\tau)}=\frac{d E(\tau)}{d \sigma(\tau)} e(\tau)
$$

Enter the designation

$$
\delta(\tau)=\frac{d E(\tau)}{d \sigma(\tau)}
$$

get the algorithm for calculating the correction weights in the form

$$
w(\tau+1)=w(\tau)+y \delta(\tau) e(\tau) .
$$

Here $\delta(\tau)$ is calculated by the formula:

$$
\begin{gathered}
\delta(\tau)=\frac{d E(\tau)}{d \sigma(\tau)}=\frac{1}{2} \frac{d}{d \sigma(\tau)}\left([\varepsilon(\tau)]^{2}\right)=\frac{1}{2} \frac{d}{d \sigma(\tau)}\left(\left[\wp_{0}-\wp(\tau)\right]^{2}\right)= \\
=-\left(\wp_{0}-\wp(\tau)\right) f_{\sigma}^{\prime}(\sigma(\tau))=-\left(\wp_{0}-\wp(\tau)\right)(1-\wp(\tau)) \wp(\tau) .
\end{gathered}
$$

Taking into account (25), the algorithm for setting the weights of the neurons is as follows:

$$
\begin{aligned}
& w_{0}(\tau+1)=w(\tau)-y\left(\wp_{0}-\wp(\tau)\right)(1-\wp(\tau)) \wp(\tau) e(\tau) \\
& w_{0}(\tau+1)=w_{0}(\tau)-y\left(\wp_{0}-\wp(\tau)\right)(1-\wp(\tau)) \wp(\tau) .
\end{aligned}
$$

Finally, taking into account (16), we obtain:

$$
\begin{aligned}
& w(\tau+1)=w(\tau)-y\left(\frac{T_{C A}}{K_{2} \cdot K \cdot m_{C h C T}}-\wp(\tau)\right)(1-\wp(\tau)) \wp(\tau) e(\tau), \\
& w_{0}(\tau+1)=w_{0}(\tau)-y\left(\frac{T_{C A}}{K_{2} \cdot K \cdot m_{C h C T}}-\wp(\tau)\right)(1-\wp(\tau)) \wp(\tau) .
\end{aligned}
$$

On the basis of the developed regulatory system, a simulation model was formalized and a computational experiment was performed in Matlab [4,7].

\section{RESULTS AND DISCUSSION}

Analysis of transients (Fig. 1) showed that with the influence of a parametric perturbation, the hybrid system has a shorter regulation time $\left(T_{r 1}=138 \mathrm{~s}\right)$ compared to traditional adaptive $\operatorname{ACS}\left(T_{r 2}=163 \mathrm{~s}\right)$, as well as overshoot hybrid ACS $G_{t r}=28 \%$ traditional $G_{t r}=50 \%$, the degree of attenuation of the hybrid $\psi^{T r}=0,91$, traditional $\psi^{T p}=0,68$, i.e. the proposed hybrid ACS is optimal and energy efficient. 


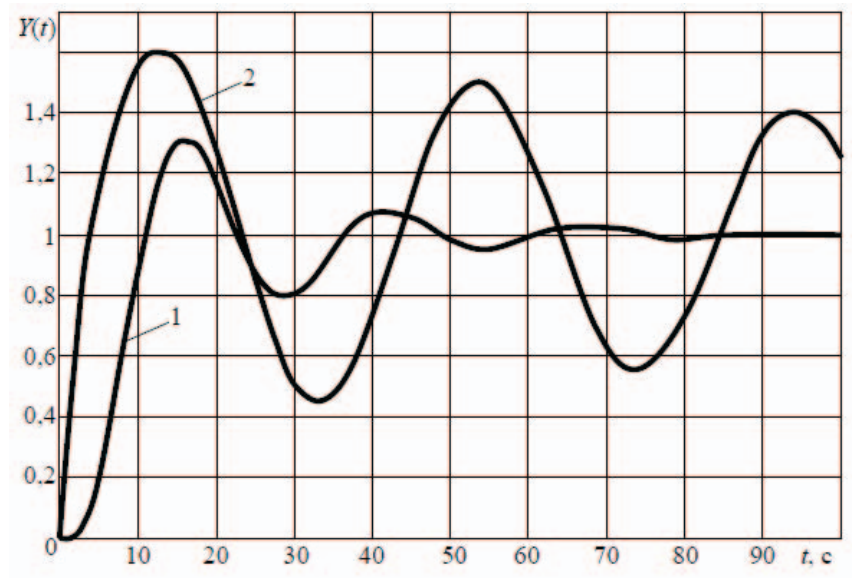

Fig. 2: Transient processes along the control channel: 1-neuro-fuzzy ACS (at nominal load), 2 - neuro-transparent ACS (when the load changes).

\section{CONCLUSION}

Based on the obtained results, it can be concluded that the proposed intelligent adaptive ACS temperature of superheated steam has the following advantages:

- the speed of the process of finding the optimal settings of the PI controller of the cascade ACS with the possibility of approximation and extrapolation;

- smaller first deviation and time of the transition process regulation;

- the possibility of optimal functioning of the cascade ACS in all modes of the steam drum boiler;

- the use of adaptive fuzzy-logic allows you to provide a fairly good quality control of the temperature of superheated steam.

- the possibility of using adaptation of various ACS of TP, ACS with PD, and PID regulators in the heat supply in the processes of adaptation.

The results of the study showed that during the control of the temperature regime of the boiler unit, a developed adaptive system of fuzzy PID regulators has a faster response, higher regulatory accuracy, and the best functioning in stationary mode. It should be noted that when using an adaptive fuzzy PID regulator, the reconstitution is reduced by $20 \%$, the control time of 35 seconds, degree attentiveness increased by 0.23 , and the control regulation decreased by $15 \%$, the dynamic characteristic of the adaptive control system with a fuzzy PID controller is improved.

The performance of the control system of adaptive fuzzy system with PID by a regulator is much better than the digital PID controller and more energy-efficient.

\section{REFERENCES}

[1] O'Dwyer A. (2009) Handbook of PI and PID Controller Tuning Rules. 3rd Edition. Dublin: Institute of Technology; Ireland, Imperial College Press. 529 p.

[2] Astrom KJ. (2006) Advanced PID control/ K. J. Astrom, T. Hagglund - ISA (The instrumentation, Systems, and Automation Society), - 460 p.

[3] Demchenko VA. (2001) Automation and modeling of technological processes at nuclear power plants and thermal power plants / V. A. Demchenko. - Odessa: Astroprint. - 308 p. 
[4] Kim T, Maruta I, Sugie T. (2008) Robust PID controller tuning based on the constrained particle swarm optimization, Automatica, 44(4): 1104-1110.

[5] Lu C, Hsu C, Juang C. (2013) Coordinated control of flexible AC transmission system devices using an evolutionary fuzzy lead-lag controller with advanced continuous ant colony optimization, IEEE Transactions on Power Systems, 28(1): 385-392.

[6] Pelusi D. (2012) PID and intelligent controllers for optimal timing performances of industrial actuators, International Journal of Simulation: Systems, Science and Technology, 13(2): 65-71.

[7] Pelusi D, Mascella R. (2013) Optimal control algorithms for second order systems, Journal of Computer Science, 9(2): 183-197.

[8] Pletnev GP. (2007) Automation of Technological Processes and Productions in HeatandPower Engineering. 4th Edition. Moscow: Publishing House Moscow Power Engineering Institute. $-352 \mathrm{p}$.

[9] Rotach VY. (2008) The Theory of Automatic Control. Moscow: Publishing House Moscow Power Engineering Institute. - 396 p.

[10] Siddikov IX, Iskandarov Z. (2018) Synthesis of adaptive-fuzzy control system of dynamic in conditions of uncertainty of information // International Journal of Advanced Research in Science, Engineering and Technology, 5(1): 5089-5093.

[11] Siddikov IX, Umurzakova DM. (2019) Features of automatic control of technological parameters of water level in the drum steam boilers, Journal of Southwest Jiaotong University, 54(3): 1-10. DOI: 10.35741/issn.0258-2724.54.3.1.

[12] Siddikov IX, Umurzakova DM. (2019) Mathematical Modeling of Transient Processes of the Automatic Control System of Water Level in the Steam Generator, Universal Journal of Mechanical Engineering, 7(4): 139-146. DOI: 10.13189/ujme.2019.070401.

[13] Sidikov IX, Umurzakova DM. (2019) Adaptive neuro-fuzzy regulating system of the temperature mode of the drum boiler // International Journal of Advanced Research in Science, Engineering and Technology, 6(1): 7869-7872.

[14] Soroko EM, Golden Sections. (2006) Processes of Self-Organizing and Evolution in Systems: Introduction into the General Theory of System Harmonizing. Moscow: KomKniga. -264 p. 